\title{
pathogens
}

ISSN 2076-0817

www.mdpi.com/journal/pathogens

Review

\section{Perturbation of the Human Microbiome as a Contributor to Inflammatory Bowel Disease}

\author{
Bayan Missaghi $^{1{ }^{*}, \text { Herman W. Barkema }}{ }^{2}$, Karen L. Madsen ${ }^{3}$ and Subrata Ghosh ${ }^{4}$ \\ 1 Department of Medicine, University of Calgary, Infection Prevention \& Control, Alberta Health \\ Services, Office 3685, 3500-26th Avenue Northeast, Calgary AB T1Y 6J4, Canada \\ 2 Department of Production of Animal Health, University of Calgary, HSC 2521, Health Sciences \\ Centre, 2500 University Drive Northwest, Calgary AB T2N 1N4, Canada; \\ E-Mail: barkema@ucalgary.ca \\ 3 Department of Medicine, University of Alberta, 7-142K Katz Building, Edmonton AB T6G 2E1, \\ Canada; E-Mail: karen.madsen@ualberta.ca \\ 4 Department of Medicine, University of Calgary, Alberta Health Services, Room 930, North Tower, \\ Foothills Medical Centre, 1403-29th St NW, Calgary T2N 4J8, Canada; \\ E-Mail: subrata.ghosh@albertahealthservices.ca \\ * Author to whom correspondence should be addressed; \\ E-Mail: bayan.missaghi@albertahealthservices.ca; Tel.: +1-403-943-4024; Fax: +1-403-291-2571.
}

Received: 26 March 2014; in revised form: 6 June 2014 / Accepted: 9 June 2014 /

Published: 30 June 2014

Abstract: The human microbiome consist of the composite genome of native flora that have evolved with humanity over millennia and which contains 150 -fold more genes than the human genome. A "healthy" microbiome plays an important role in the maintenance of health and prevention of illness, inclusive of autoimmune disease such as inflammatory bowel disease (IBD). IBD is a prevalent spectrum of disorders, most notably defined by Crohn's disease (CD) and ulcerative colitis (UC), which are associated with considerable suffering, morbidity, and cost. This review presents an outline of the loss of a normal microbiome as an etiology of immune dysregulation and IBD pathogenesis initiation. We, furthermore, summarize the knowledge on the role of a healthy microbiome in terms of its diversity and important functional elements and, lastly, conclude with some of the therapeutic interventions and modalities that are now being explored as potential applications of microbiome-host interactions. 
Keywords: microbiota; metagenome; microbiome; inflammatory bowel disease; ulcerative colitis; Crohn's Disease

\section{Introduction}

The human microbiome is the collective genome of indigenous microbiologic flora that has evolved with mankind over millennia. From the moment of birth, each part of the body becomes colonized by characteristic populations of organisms belonging to each of the three domains of life, Archaea, Bacteria and Eukarya [1,2]. However, the human gut microbiome is particularly distinct in that it is home to a plethora of bacteria, an estimated 100 trillion cells, which is approximately 10 -fold more than the total number of human cells [3] and which encodes for 150-fold more unique genes than our own genome [4]. The majority of these bacteria cannot easily be cultivated using traditional culture techniques, and it has only been since the application of sequencing technology that the complement of human flora has been described in greater complexity [5]. Our species has co-evolved with these micro-organisms in a mutualistic fashion, and we have come to rely on them for many processes including immune system maturation, nutrition, maintenance of intestinal barrier permeability and function, and prevention of infection with pathologic species [3]. Indeed, the gut microbiota reside in close proximity to the luminal surface of the large and small bowel, placing them in near proximity to the immune system, and endowing them with a key role in immune function and maturation [6]. It has become increasingly clear that this fragile balance of organisms has many important associations with regards to the maintenance of health and the prevention of illness. It was our aim to review some of these concepts with a special emphasis on the role of the intestinal microbiota in inflammatory bowel disease (IBD).

It has been suggested that individuals can be categorized into three distinct enterotypes that are separated by dominance in the proportions of one of three genera: Bacteroides (enterotype 1), Prevotella (enterotype 2), and Ruminococcus (enterotype 3) [7]. These clusterings appear to have developed in response to primarily dietary environmental factors [7]. In this original study, the authors concluded that the robustness of these enterotypes across populations, as well as across phylogenetic and functional levels, was indicative of the fact that they appear to be the result of a limited number of well-balanced discrete bacterial community compositions [7]. However, more recent studies have demonstrated the existence of abundance gradients rather than distinct clustering, and have shown that the type of methodology used to examine microbiome composition can have significant effects on conclusions drawn [8].

\section{Microbiome Alterations and Inflammatory Bowel Disease Immune Dysregulation}

Inflammatory bowel disease is a chronic inflammatory disorder of the intestinal tract that is associated with abdominal pain, intestinal bleeding, weight loss, and diarrhea. The two most common forms of the condition include Crohn's disease (CD) and ulcerative colitis (UC) [9]. These diseases are associated with considerable morbidity, and place a significant burden on individuals, families, and society, accounting for an estimated $\$ 1.8$ billion of expense per year in Canada alone [10,11]. The 
cause of IBD remains unknown; however, it is thought to occur in genetically-predisposed individuals who are exposed to microbial, dietary, and environmental triggers [12]. The incidence of IBD has increased dramatically in developed countries over the past 50 years and has been linked with modernization and Western lifestyles [11]. Environmental risk factors are an essential component in the pathogenesis of IBD and are believed to be largely responsible for the rapid increase in world-wide incidence [12]. Please refer to Box 1.

Box 1. Factors affecting the microbiome.

\begin{tabular}{ll|}
\hline - Age \\
- Denetics \\
- Medications (antibiotics, etc.) \\
- Smoking status \\
- Obesity \\
\hline
\end{tabular}

In infants, gut microbial communities undergo radical compositional and functional changes in response to environmental exposures until a relatively stable community becomes established by approximately 2-3 years of age [13]. Establishment of the gut microbiome is influenced by early diet, antibiotic exposure, and method of birth, breast milk composition, and genetic background [14-17]. Antibiotic use during this period can significantly alter the composition of the gut microbiota and result in long term decreases in diversity and altered trajectories of immune development, which can modulate susceptibility to disease in later life $[13,18,19]$. Indeed, antibiotic exposure and infections during the first year of life have been identified as independent risk factors for IBD [20-22]. This is due to the fact that gut microbiota play an important role in immune regulation and barrier function of the gut, and that consequent alteration thereof may result in the loss of tissue integrity [23]. Both the innate and adaptive arms of the immune system have been shown to play a role in IBD, with altered adaptive immune function being the primary contributor to disease pathogenesis [6]. In general, this occurs mainly through increased pro-inflammatory cytokines driven by the T-helper subsets or by lack of effective anti-inflammatory regulatory T-cells [6].

Changes in innate immunity are also important and evidence exists that alterations in innate immune function are the primary driver of dysfunctional adaptive immune responses. It has been demonstrated that intestinal epithelial cells may directly or indirectly recognize luminal micro-organisms, and that toll-like receptors (TLRs) may be essential in the maintenance of epithelial cell homeostasis [24]. TLRs are specialized trans-membrane receptors of the interleukin-1 superfamily, which recognize and respond to pathogen-associated molecular patterns (PAMPS). The interactions between such TLRs and their ligands are involved in the clearance of pathogenic bacteria, leukocyte recruitment, epithelial homeostasis, and maintenance of barrier immunity. Many TLRs are upregulated in IBD once inflammation is established due to the increased presence of TLR promoter inducers, including inflammatory cytokines and NF-KB [24]. A loss of TLR signaling homeostasis in either direction, either an increase or decrease in activity, is thought to play a potential role in IBD pathogenesis [25]. 
Nucleotide-binding oligomerization domain-containing protein 2 (NOD2), also known as caspase recruitment domain-containing protein 15 (CARD15), is a protein which plays an important role in immune system functioning via recognition of bacterial molecules (such as peptidoglycans) and stimulation of appropriate responses. NOD2 alleles are mutated in approximately $15 \%$ of CD patients, and this can result in defective neutrophil recruitment in these patients as a result of NOD2 and interleukin 8 (IL-8), and NOD2 and TLR receptor pathway interactions [26]. This supports the concept that the adaptive immune dysfunction in CD may occur due to a failure to receive an early priming signal to pathogenic micro-organisms, resulting in a failure to clear them and the development of abnormal subsequent immune responses to their antigens. Studies now suggest that CD patients with abnormal NOD2 have an increased susceptibility to the generation of strongly polarised Th1 responses, resulting in an overly aggressive adaptive immune response to common intestinal flora and thereby setting the stage for IBD [27].

The general concept of immune dysregulation has led credence to the "hygiene hypothesis", a theory that has been advanced as a possible explanation for the increased incidence of IBD, which claims that improvements in hygiene-particularly in developed countries - are congruent with a rise in autoimmune illnesses $[9,11]$. Strachan (1989) was the first scientist to connect this hypothesis to an increase in allergic diseases and believed that a child could be overly protected from exposure to microbes with lack of exposure to these agents, in early childhood, resulting in more widespread clinical expression of atopy [28] due to immune aberrancy. It is for this reason that many scientists now advocate for a moderate approach towards cleanliness in young children [29].

\section{Microbiome Bacterial Dysbiosis in IBD Pathogenesis}

A growing body of literature implicates the abnormal overgrowth or dominance of particular bacterial species, at the expense of others, in the pathogenesis of IBD. Notably, mouse model studies of IBD have shown protection against the development of IBD in a germ-free environment, and lend credence to the role of gut flora in the pathogenesis of this spectrum of illnesses [30]. Furthermore, other studies have revealed that the intestinal flora of patients with IBD have less bacterial species diversity and less stability over time, suggestive of an association between alteration of the human microbiota and development of this type of disease [31]. In healthy hosts, Firmicutes, felt to contribute in a key fashion to micronutrient metabolism, are amongst the most dominant constituents of the human indigenous gut microflora, accounting for the largest proportion (75\%) of bacteria [2]. Several studies to date [32-34] have demonstrated reduced Firmicutes, in particular Faecalibacterium prausnitzii and Roseburia, and increased Ruminococcus and Enterobacteriaceae, especially adherent invasive Escherichia coli (AIEC), in IBD [35-45].

Some research to date has demonstrated an increased prevalence of Escherichia coli in the ileum of CD patients [36], and a very recent study has shown the ability of E. coli to trigger and potentiate intestinal inflammation in mouse models [46]. Despite, the association of this particular organism with IBD and, in particular, CD, the precise role of adherent-invasive E. coli (AIEC) in the initiation or activation of IBD is not yet fully defined. However, there is evidence for upregulation of microRNAs, which reduce expression of proteins necessary for the autophagy response in intestinal cells [47]. This suggests that such infected epithelial cells are prevented from self-degradement and recycling of cell 
components. One theory is that AIEC strains, having the capability of adhering to and invading both intestinal epithelial cells and macrophages, can translocate across the bowel wall and continuously activate further macrophages, leading to the formulation of granulomas [36]. It is known that micro-organisms that are able to penetrate the bowel epithelial barrier and to bypass macrophage killing can trigger a powerful and long lasting inflammatory response [48,49].

Other research has reported an interesting increased prevalence of other organisms, including Mycobacterium avium subspecies paratuberculosis (MAP) in the intestinal tissue of CD patients [50,51]. MAP has been defined as the etiology of Johne's disease in cattle, a chronic granulomatous illness that is clinically and pathologically similar to CD in humans [52]. Moreover, several studies have revealed that a high proportion of CD patients are infected with MAP compared to persons not having IBD [53]. In fact, a fairly recent imputation-based association analysis was quite conclusive in the overlap and correlation shown between susceptibility loci for CD and infection with MAP [54]. Unfortunately, however, no research to date has either confirmed or denied the precise role of any particular organisms in IBD. In fact, the source of MAP in humans is felt by some researchers to be either an environmental or zoonotic epiphenomenon. A two-year study by Selby et al. revealed that empiric therapy typically effective against MAP, with clarithromycin, rifabutin, and clofazimine for up to two years, did not provide sustained benefits [55]. On the other hand, using the data from this study, one can also refute the conclusions drawn, noting that the antibiotic arm did significantly better than the control arm for as long as antibiotics were administered [56]. This is suggestive that MAP is a significant player in at least a subset of IBD patients, and that this type of therapy may be effective for them. Further study will be necessary to sort out this controversy.

An emerging theory is that a dysbiosis or imbalance of intestinal flora may be a trigger for IBD in those who may be susceptible, a problem that is normally avoided through the maintenance of a healthy microbiome. There are many reasons why the presence of normal healthy commensal organisms prevents this process from occurring. One is that commensal microbes resist colonization by enteric the pathogens listed above, both directly and indirectly [57]. There are several ways in which this is achieved. Firstly, the most basic method in which normal microbiota favour resistance against opportunistic infection is via niche competition. This involves competition for sites of colonization and nutrient uptake at host epithelial surfaces [58], and modulation of protective immune responses [57]. Another modality by which commensal organisms help resist colonization by bacteria associated with IBD is by promotion of barrier immunity. An example of this would be induction of epithelial production of mucin, secretion of mucosal immunoglobulins and the expression of antimicrobial peptides via host TLR recognition of PAMPs [57] as alluded to previously. Yet a third modality of pathogen resistance relates to the anaerobic environment of the bowels, a factor which allows particular gut commensals to harness energy via fermentation of nutrients passing through the lumen, resulting in the production of short chain fatty acids (SCFAs). SCFAs include acetate, butyrate and propionate, and are resistant starches that are generally not well digested in the upper GI tract [59]. SCFAs strengthen the intestinal epithelium by increasing tight junction protein (TJP) production and by increasing transepithelial electrical resistance (TEER) [2] as well as by affecting the immune system directly [60]. Thus, it is clear that diet, too, by selecting for particular micro-organisms and by resulting in specific metabolites, has a profound impact on the selection of existing normal intestinal flora. 


\section{The Microbiome, Obesity and CD}

The worldwide obesity epidemic has more than doubled since 1980, and this condition is associated not solely with metabolic disorders, including type 2 diabetes and cardiovascular disease, but also with a wide variety of disorders such as cancer, sleep apnea, osteoarthritis and gallbladder disease [61]. Though the present view is that the major etiology of obesity is unbalanced energy intake and expenditure in association with genetic predisposition, environmental factors may also play a role. Amongst the important outside factors impacting the host's response to diet is the gut microbiome [62]. The initial demonstration of particular alterations in composition between the intestinal flora of obese and lean phenotypes was made in leptin-deficient mice, in which the guts of obese mice contained fewer Bacterioidetes and increased Firmicutes than other mice [63]. Subsequent studies revealed that the transfer of obese mouse gut flora to germ-free mice could reproduce the donor obese phenotype in the recipient mice [64], and several recent studies, using pyrosequencing and advanced PCR techniques, have demonstrated that high-fat diets increase the Firmicutes/Bacterioidetes ratio and decrease Bifidobacterium spp. [65]. Moreover, a higher abundance of Ruminococcaceae and Rikenellaceae was seen in leptin-resistant obese and diabetic mice than their slim counterparts [66]. Of some interest, it has also been shown that bacterial ATPase complexes correlate strongly with human BMI, further supporting the association between the intestinal flora's capacity for energy harvest and obesity in the host [67]. Moreover, adipocytes have been demonstrated to release a variety of proinflammatory cytokines and peptides, and it is believed that visceral adiposity may play an important role in the commencement and maintenance of inflammation in CD [68]. Based on a time-trend analysis from data collected between 1991 and 2008, a clear correlation has been shown between increasing weight over time and CD [68].

\section{Human Gut Microbiome Diversity and Functional Changes}

It has recently been discovered that the evolutionary composition of gut bacterial flora, regardless of geography, evolves towards an "adult" phenotype by the third year of life [69]. Furthermore, regardless of geography, interpersonal variation in gut flora is greater between children than between adults [69]. Moreover, microorganism diversity increases with age, and there are significant phylogenetic differences amongst populations living in different countries and regions [69]. Many of these differences are due to diet and the availability of particular nutrients in the environment with increases in proportions of various bacterial species found to be primarily related to functional requirements. For example, individuals living in rural Africa and South America have gut microbiomes that are more similar to those of herbivorous animals, whereas Western microbiomes are more reflective of those of carnivores [70]. Thus, these are clear adaptations determined in response to varying diets in these regions.

Over the past several years some interesting trends were discovered in regards to functions of gut micobiota. Though some studies have shown clear variability in the composition of human microbiota over time, the functional potential of the microbiome remains strikingly stable [71]. Using metagenomic approaches, it has been shown that $12 \%$ of gut-related metabolic pathways are different between IBD patients and healthy controls versus only $2 \%$ of genus-level clades in this context [72]. In 
keeping with taxonomic profiling studies revealing lessening numbers of Firmicutes, one metagenomic trend that has been shown is that there is a reduction in butyrate and propionate metabolism genes in CD [72], as well as lower levels of other SCFAs [43]. There is also an increase in functions associated with auxotrophic bacteria, including a decrease in amino acid biosynthesis, and an increase in amino acid transfer [72]. Given the presence of tissue destruction in inflammatory conditions, these bacteria tend to thrive in such conditions where nutrients are easily accessible in the environment [72]. Furthermore, studies have shown an increase in sulphate-reducing bacteria in IBD, an interesting fact when one considers that a mechanism of a common medical treatment for IBD, mesalamine, is the inhibition of fecal sulphide production [73]. Genes that take part in the metabolism of the sulfa-containing amino acid cysteine are increased in IBD, as is increased sulphate transport [72].

\section{Impact of Cigarette Smoking on the Microbiome}

Other environment factors also impact the gut microbiota. Smoking is an important risk factor in IBD pathogenesis with most studies showing a protective effect of cigarette smoking in UC and a deleterious effect in CD [74,75]. Smoking cessation induces prominent alterations in the composition of normal intestinal flora [76]. After cigarette cessation, comparable shifts have been seen in flora composition as have been described in obese versus lean humans and mice $[63,77]$; specifically, an increase in the proportion of Firmicutes relative to Bacterioidetes. Moreover, a concurrent mean weight gain of $2.2 \mathrm{~kg}$ occurred during the observation period of these mice, in the absence of alterations in total calorie intake or other dietary changes [76], suggesting a role of commensal organism changes and consequent metabolic alterations in pathogenic weight gain post smoking cessation. However, the precise molecular and cell effects of smoking and smoking cessation on gut microbiota continue to be relatively poorly understood and are an area for further detailed study.

\section{Impact of Antimicrobial Therapy on the Microbiome}

It is well known that, since the 1950s, antibiotics have been liberally used in the agricultural industry as growth promoters, though the mechanism for this effect has been poorly understood. Notably, in Canada and the U.S., the heaviest use of such antimicrobials is within farms, with restricted doses fed to livestock in order to increase their growth by up to $15 \%$ [78,79]. Interestingly, these effects have shown to be relatively consistent across a broad variety of vertebrate species, including mammals (cattle, swine, sheep) and birds (chickens, turkeys), and follow oral administration of these antibiotics, suggesting that the gastrointestinal microbiota may be a notable target [80]. Moreover, the fact that these effects are not agent specific and have been shown true for macrolides, tetracyclines, pencillins, and other agents, indicates that these growth effects are not side effects associated with a particular class of antimicrobials. Within this context, it has been postulated that sub-therapeutic administration (STA) of such molecules may modify the structure of the gut microbiome and its metabolic function to a significant extent [80]. In fact, we know well that antibiotics can have a great effect on the composition of the microbiome in comparison to other environmental factors. As alluded to earlier, antibiotics administered within the first year of life are believed to cause atrophy of the microbiome and to increase the risk of future autoimmune disease as a consequence [20]. 
Interestingly, murine model studies have confirmed that STA of antimicrobials can both increase adiposity in mice, as well as increase hormone levels that play a role in metabolism by altering the proportions of various microbiota. Specifically, one recent novel study showed that an increase in relative concentrations of Firmicutes compared to Bacterioidetes in mice treated with STA of antibiotics [80]. Perhaps even more interestingly, STA of these molecules were shown in this study to stimulate adipogenesis by increasing SCFA levels and, thereby, by providing direct energy to colonocytes [80], confirming some of the functional pathway alterations that occur as a result of antimicrobial administration. This loss of equilibrium and homeostasis may become substantial when prolonged, and may result in changes in host health and subsequent disease [81]. Indeed, murine studies are currently being explored to define models for a variety of diseases related to microbiome shifts and alterations as a result of antimicrobial use.

\section{Therapeutic Approaches and Applications of the Microbiome}

Though antimicrobials have a well-established role in the treatment of septic complications of IBD, their benefit in treating the underlying disease process is more controversial. A number of controlled trials and observational studies have been published over the last 30 years regarding the use of antibiotics in treating CD [82-84]. Most of these are small studies of short duration and with significant methodological disadvantages, including the use of different endpoints and outcomes. However, a 2011 meta-analysis of randomized controlled trials revealed superiority of antibiotics to placebo in the induction of remission of active CD as well as in the maintenance of remission [85]. Another meta-analysis of 10 randomized trials in 2012 demonstrated an improvement in symptoms in IBD patients treated with antibiotics as opposed to placebo [86]. Regarding UC, the 2011 meta-analysis showed a modest benefit in induction of remission of active disease via antibiotics relative to placebo [85], though less promising than in CD. In reference to the study by Selby et al., though anti-tuberculosis treatment has shown some benefit in $\mathrm{CD}$, it is unclear whether this is as a result of the treatment of MAP, the treatment of other commensal organisms or via other nonspecific anti-inflammatory effects [55]. In terms of the choice of antimicrobial regimen, though there is significant variation and little standardization in the literature, most would advocate for the use of a combination of ciprofloxacin and metronidazole based primarily on clinical experience.

Probiotics are "live micro-organisms which, when administered in adequate amounts, confer a health benefit on the host" [87]. Indeed, several studies in mouse models have demonstrated prevention of the onset of colitis and reduction of inflammation in established disease using Lactobacillus spp. and mixed culture supplementation [88-90]. However, clinical data on the use of probiotics in humans is limited and most studies have not been placebo controlled [91]. Moreover, more study is needed on the properties of different bacterial strains for various indications, as well as information on combinations, dosage and duration of therapy. A related intervention involves the use of prebiotics, food ingredients that are not digested or absorbed in the upper GI tract and which are fermented in the lower GI tract, promoting the growth of micro-organisms with beneficial effects. For instance, inulin and oligofructose are fermented in the large intestine and encourage the growth of native lactobacilli and bifidobacteria among other organisms, effects which are associated with reduced mucosal inflammation in animal models of IBD [92]. 
Fecal microbiota transplantation (FMT) is a procedure, which has rapidly grown in acceptability and popularity over the past decade. In the animal kingdom, coprophagy (consumption of feces) is quite common and observed in a variety of species [93,94]. The practice of transfaunation, the transfer of gastrointestinal contents, between animals has been practiced for centuries by veterinarians and, whether conducted naturally or artificially, contributes to accelerated maturation of the gut, enhanced digestion of nutrients and increased resistance to colonization of the gut by pathogenic organisms [95]. Historically, despite an innate repugnance for stool, human civilization has used variations of FMT for thousands of years. The earliest known documentation of this comes from Chinese medicine, referring to the use of various fecal preparations for the treatment of human gastrointestinal illnesses [96]. However, there are also examples of such practice in other parts of the world, including Europe in the late 1600s, where Dr. Franz Paullini, a German physician, published a book on the uses of human and animal feces entitled Hailsame Dreck-Apotheke (Salutary Filth-Pharmacy) [95].

In modern times, FMT has been hailed as an extremely effective therapeutic procedure for treatment refractory Clostridium difficile infection (CDI) [97]. At this point in time, the FDA is allowing the use of FMT for CDI that remains refractory to other therapeutic modalities. Given the success of FMT for this indication, it would be sensible to believe that this procedure or derivatives thereof may eventually be applied to several other medical conditions on a more regular basis, including IBD. Some researchers now advocate for the streamlining of FMT by such interventions as "auto-banking," in which a sample of patients' stool is collected and frozen on admission to an inpatient facility for later implantation after completion of antimicrobial therapy [98]. Though theoretically reasonable, such methods will certainly require further study and approval by regulatory bodies.

In the context of increasing evidence of the importance of our normal microbiota for the maintenance of health and prevention of disease, there has been a recent explosion of interest in modulating the microbiome to restore balance and promote health. One such application, a derivative of FMT, has been labelled as "Microbial Ecosystem Therapeutics" (MET) and involves the replacement of a damaged and/or dysfunctional microbiota with a fully developed and "healthy" constellation of intestinal bacteria in a synthetic fashion [99]. As opposed to traditional probiotic therapies, which involve the use of a single strain or a few strains of bacteria, MET involves the application of entire intestinal bacterial populations, which more closely resemble our own normal flora. The potential implications for such therapy are vast and include the treatment of CDI in addition to IBD, irritable bowel syndrome (IBS), obesity and metabolic syndrome, and even certain types of autism [99].

However, it should be noted that at present the use of FMT or MET for non-CDI indications is an area of intense study and that the optimal approaches appear unclear. Despite anecdotal reports of successful treatment of UC and CD [100,101], others, including Kump et al., have reported no clinical improvement in small series of patients with UC [102]. It is clear that this is a ripe area for further research.

Moreover, SCFAs, the main metabolic products of anaerobic fermentation in the bowel, have been recognized as important mediators in intestinal epithelial barrier permeability and immune function [60]. Indeed, higher concentrations of such fatty acids in the intestines and in the blood have a direct impact on reduction of predisposition to or intensity of inflammatory conditions, including IBD and cancer [60]. In this context, many researchers are now considering the potential therapeutic applications of SCFAs and their derivatives in the treatment of IBD [103-105]. Though results have been quite positive overall, further study is necessary to establish the dose, frequency and form of SCFA products to 
receive ideal results. Yet another implication of this research is the use of potential SCFA receptor agonists to achieve desired effects in terms of strengthening intestinal barrier permeability and priming the immune system.

Though the use of antimicrobials leading to selection of multi-drug resistant organisms (MDROs) is a growing cause for concern, many researchers would now argue that the likelihood of such medications to disturb indigenous flora, facilitating the spread of prior selected resistant strains or their resistant traits, is even more important [98]. This pressure on the microbiome will, of course, not only impact individual patients, but the whole of society as MDROs continue to spread as a result. Several important studies have now demonstrated that our current antibiotics, though effective as anti-infective agents, can cause significant collateral harm to our microbiome [106,107]. In this context, another important application of the microbiome in therapeutics involves studying the impact that each of our current antimicrobial classes makes in this realm, and to put stewardship measures in place to favour the use of drugs that have a low microbiome damage profile. This approach could be further expanded to the preclinical drug approval process to ensure that our drugs in development have the lowest possible impact on the status of our normal commensals [107]. Not only will this aid in improving the outcomes of individual patients, but will also help with infection control efforts to prevent and/or shorten the duration of MDRO colonization.

Furthermore, other researchers have advocated for the use of specific medications to be given after an antimicrobial course is complete in order to break down or bind any residual drug that will only serve to further damage the microbiome [108,109]. Indeed, there is a time lag of several weeks to months (and sometimes longer) between the final administration of antimicrobials and reconstitution of the microbiome to pre-treatment levels. This delay, in animal models, is linked with an increased propensity to secondary infections [110].

As we look to the future and as more knowledge is gained regarding host-microbiome interactions and the biochemical and immunologic interactions that lead to the release of antimicrobial peptides and maintenance of barrier immunity, desired effects may be achieved through novel modalities and approaches. Perhaps, we may one day manipulate the host into producing the peptides produced by an intact and healthy microbiome through the application of bacterial antigens or, better yet, the administration of purified peptides and other protective molecules without the need for application of live micro-organisms [98]. This will allow healthcare providers to artificially assist with healing the host intestinal barrier without subjecting the patient to the fecal transplant-associated risk of pathogen transmission and will avoid the inherent aversion to receiving a FMT.

\section{Conclusions}

Environmental factors, including the microbial composition of the gut, may be as important as genetic determinants in the pathogenesis of IBD, such as CD and UC. However, many details are yet to be determined. Despite this, it is clear that IBD disease pathogenesis involves a combination of an aberrant immune system along with dysbiosis in the gut microbiome. Further study and a better understanding of important host-microbial interactions will allow us to accelerate our development of novel therapeutic applications, such as FMT and MET, the use of innovative scoring systems for the impact of antimicrobials on the microbiome, and the hopeful eventual use of purified peptides and 
other molecules. The ultimate goal will be to optimally restore the normal and healthy mutualistic balance between the host and microbiota, which has existed for millennia.

\section{Author Contributions}

Dr. Missaghi conducted the literature review, which provided the background for the composition of this manuscript. Dr. Missaghi, Dr. Barkema, Dr. Madsen and Dr. Ghosh were all involved in the writing and editing of this manuscript.

\section{Conflicts of Interest}

The authors declare no conflict of interest.

\section{References}

1. Weinstock, G.M. Genomic approaches to studying the human microbiota. Nature 2012, 489, 250-256.

2. Guzman, J.R.; Conlin, V.S.; Jobin, C. Diet, Microbiome, and the Intestinal Epithelium: An Essential Triumvirate. Biomed. Res. Int. 2013, 2013, 1-12.

3. Wu, G.D.; Lewis, J.D. Analysis of the Human Gut Microbiome and Association With Disease. Clin. Gastroenterol. Hepatol. 2013, 11, 774-777.

4. Qin, J.; Li, R.; Raes, J.; Arumugam, M.; Burgdorf, K.S.; Manichanh, C.; Nielsen, T.; Pons, N.; Levenez, F.; Yamada, T.; et al. A human gut microbial gene catalogue established by metagenomic sequencing. Nature 2010, 464, 59-67.

5. Penders, J.; Stobberingh, E.E.; Savelkoul, P.H.M.; Wolffs, P.F.G. The human microbiome as a reservoir of antimicrobial resistance. Front. Microbiol. 2013, 4, 1-7.

6. Wallace, K.L.; Zheng, L.; Kanazawa, Y.; Shih, D.Q. Immunopathology of inflammatory bowel disease. World J. Gastroenterol. 2014, 20, 6-21.

7. Arumugam, M.; Raes, J.; Pelletier, E.; Paslier, D.L.; Yamada, T.; Mende, D.R.; Fernandes, G.R.; Tap, J.; Bruls, T.; Batto, J.; et al. Enterotypes of the human gut microbiome. Nature 2011, 473, 174-180.

8. Koren, O.; Knights, D.; Gonzalez, A.; Waldron, L.; Segata, N.; Knight, R.; Huttenhower, C.; Ley, R.E. A Guide to Enterotypes across the Human Body: Meta-Analysis of Microbial Community Structures in Human Microbiome Datasets. PLoS Comput. Biol. 2013, 9, e1002863.

9. Koloski, N.A.; Bret, L.; Radford-Smith, G. Hygiene hypothesis in inflammatory bowel disease: A critical review of the literature. World J. Gastroenterol. 2008, 14, 165-173.

10. Rocchi, A.; Benchimol, E.I.; Berstein, C.N.; Bitton, A.; Feagan, B.; Panacionne, R.; Glasgow, K.W.; Fernandes, A.; Ghosh, S. Inflammatory bowel disease: A Canadian burden of illness review. Can. J. Gastroenterol. 2012, 26, 811-817.

11. Molodecky, N.A.; Soon, I.S.; Rabi, D.M.; Ghali, W.A.; Ferris, M.; Chernoff, G.; Benchimol, E.I.; Panaccione, R.; Ghosh, S.; Barkema, H.W.; et al. Increasing incidence and prevalence of the inflammatory bowel diseases with time, based on systematic review. Gastroenterology 2012, 142, 46-54. 
12. Ng, S.C.; Bernstein, C.N.; Vatn, M.H.; Lakotos, P.L.; Loftus, E.V., Jr.; Tysk, C.; O’Morain, C.; Moum, B.; Colombel, J.F. Geographical variability and environmental risk factors in inflammatory bowel disease. Gut 2013, 62, 630-649.

13. Sharon, I.; Morowitz, M.J.; Thomas, B.C.; Costello, E.K.; Relman, D.A.; Banfield, J.F. Time series community genomics analysis reveals rapid shifts in bacterial species, strains, and phage during infant gut colonization. Genome. Res. 2013, 23, 111-120.

14. Fallani, M.; Young, D.; Scott, J.; Norin, E.; Amarri, S.; Adam, R.; Aguilera, M.; Khanna, S.; Gil, A.; Edwards, C.A.; et al. Intestinal microbiota of 6-week-old infants across Europe: geographic influence beyond delivery mode, breast-feeding, and antibiotics. J. Pediatr. Gastroenterol. Nutr. 2010, 51, 77-84.

15. Cabrera-Rubio, R.; Collado, M.C.; Laitinen, K.; Salminen, S.; Isolauri, E.; Mira, A. The human milk microbiome changes over lactation and is shaped by maternal weight and mode of delivery. Am. J. Clin. Nutr. 2012, 96, 544-551.

16. Jakobsson, H.E.; Abrahamsson, T.R.; Jenmalm, M.C.; Harris, K.; Quince, C.; Jernberg, C.; Bjorksten, B.; Engstrand, L.; Andersson, A.F. Decreased gut microbiota diversity, delayed Bacteroidetes colonisation and reduced Th1 responses in infants delivered by Caesarean section. Gut 2014, 63, 559-566.

17. Lin, A.; Bik, E.M.; Costello, E.K.; Dethlefsen, L.; Haque, R.; Relman, D.A.; Singh, U. Distinct distal gut microbiome diversity and composition in healthy children from Bangladesh and the United States. PLoS One 2013, 8, e53838.

18. Fouhy, F.; Guinane, C.M.; Hussey, S.; Wall, R.; Ryan, C.A.; Dempsey, E.M.; Murphy, B.; Ross, R.P.; Fitzgerald, G.F.; Stanton, C.; Cotter, P.D. High-throughput sequencing reveals the incomplete, short-term recovery of infant gut microbiota following parenteral antibiotic treatment with ampicillin and gentamicin. Antimicrob. Agents Chemother. 2012, 56, 5811-5820.

19. Bakhtiar, S.M.; LeBlanc, J.G.; Salvucci, E.; Ali, A.; Martin, R.; Langella, P.; Chatel, J.M.; Miyoshi, A.; Bermudez-Humaran, L.G.; Azevedo, V. Implications of the human microbiome in Inflammatory Bowel Diseases. FEMS Microbiol. Lett. 2013, 342, 10-17.

20. Shaw, S.Y.; Blanchard, J.F.; Bernstein, C.N. Association between the use of antibiotics in the first year of life and pediatric inflammatory bowel disease. Am. J. Gastroenterol. 2010, 105, 2687-2692.

21. Hviid, A.; Svanstrom, H.; Frisch, M. Antibiotic use and inflammatory bowel diseases in childhood. Gut 2011, 60, 49-54.

22. Neuman, M.G.; Nanau, R.M. Inflammatory bowel disease: Role of diet, microbiota, life style. Transl. Res. 2012, 160, 29-44.

23. Khanna, S.; Tosh, P.K. A clinician's primer on the role of the micrbiome in human health and disease. Mayo. Clin. Proc. 2014, 89, 107-114.

24. Fukata, M.; Abreu, M.T. TLR4 signalling in the intestine in health and disease. Biochem. Soc. Trams. 2007, 35, 1473-1478.

25. Cario, E. Bacterial interactions with cells of the intestinal mucosa: Toll-like receptors and NOD2. Gut 2005, 54, 1182-1193. 
26. Van Heel, D.A.; Ghosh, S.; Butler, M.; Hunt, K.A.; Lundberg, A.M.; Ahmad, T.; McGovern, D.P.; Onnie, C.; Negoro, K.; Goldthorpe, S.; et al. Muramyl dipeptide and toll-like receptor sensitivity in NOD2-associated Crohn's disease. Lancet 2005, 365, 1794-1796.

27. Butler, M.; Chaudhary, R.; Van Heel, D.A.; Playford, R.J.; Ghosh, S. NOD2 activity modulates the phenotype of LPS-stimulated dendritic cells to promote the development of T-helper type 2-like lymphocytes-Possible implications for NOD2-associated Crohn's disease. J. Crohns Colitis 2007, 1, 106-115.

28. Strachan, D.P. Hay fever, hygiene, and household size. Br. Med. J. 1989, 299, 1259-1260.

29. Kramer, A.; Bekeschus, S.; Broker, B.M.; Schleibinger, H.; Razavi, B.; Assadian, O. Maintaining health by balancing microbial exposure and prevention of infection: the hygiene hypothesis versus the hypthesis of early immune challenge. J. Hosp. Infect. 2013, 83, S29-S34.

30. Mizoquchi, A. Animal models of inflammatory bowel disease. Prog. Mol. Biol. Transl. Sci. 2012, 105, 263-320.

31. Walker, A.W.; Sanderson, J.D.; Churcher, C.; Parkes, G.C.; Hudspith, B.N.; Rayment, N.; Brostoff, J.; Parkhill, J.; Dougan, G.; Petrovska, L. High-throughput clone library analysis of the mucosa-associated microbiota reveals dysbiosis and differences between inflamed and non-inflamed regions of the intestine in inflammatory bowel disease. BMC Microbiol. 2011, 11, 7.

32. Sha, S.; Xu, B.; Wang, X.; Zhang, Y.; Wang, H.; Kong, X.; Zhu, H.; Wu, K. The biodiversity and composition of the dominant fecal microbiota in patients with inflammatory bowel disease. Diagn. Micr. Infec. Dis. 2013, 75, 245-251.

33. Aomatsu, T.; Imaeda, H.; Fujimoto, T.; Takahashi, K.; Yoden, A.; Tamai, H.; Fujiyama, Y.; Andoh, A. Terminal restriction fragment length polymorphism analysis of the gut microbiota profiles of pediatric patients with inflammatory bowel disease. Digestion 2012, 86, 129-135.

34. Andoh, A.; Kuzuoka, H.; Tsujikawa, T.; Nakamura, S.; Hirai, F.; Suzuki, Y.; Matsui, T.; Fujiyama, Y.; Matsumoto, T. Multicenter analysis of fecal microbiota profiles in Japanese patients with Crohn's disease. J. Gastroenterol. 2012, 47, 1298-1307.

35. Glasser, A.L.; Boudeau, J.; Barnich, N.; Perruchot, M.H.; Colombel, J.F.; Darfeuille-Michaud, A. Adherent Invasive Escherichia coli Strains from Patients with Crohn's Disease Survive and Replicate within Macrophages without Inducing Host Cell Death. Infect. Immun. 2001, 69, 5529-5537.

36. Darfeuille-Michaud, A.; Boudeau, J.; Bulois, P.; Neut, C.; Glasser, A.L.; Barnich, N.; Bringer, M.A.; Swidsinski, A.; Beaugerie, L.; Colombel, J.F. High Prevalence of Adherent-Invasive Escherichia coli Associated with Ileal Mucosa in Crohn's Disease. Gastroenterology 2004, 127, 412-421.

37. Sokol, H.; Seksik, P.; Rigottier-Gois, L.; Lay, C.; Lepage, P.; Podglajen, I.; Marteau, P.; Dore, J. Specificities of the fecal microbiota in inflammatory bowel disease. Inflamm. Bowel Dis. 2006, 12, 106-111.

38. Swidsinski, A.; Loening-Baucke, V.; Theissig, F.; Engelhardt, H.; Bengmark, S.; Koch, S.; Lochs, H.; Dorffel, Y. Comparative study of the intestinal mucus barrier in normal and inflamed colon. Gut 2007, 56, 343-350.

39. Sokol, H.; Seksik, P.; Furet, J.P.; Firmesse, O.; Nion-Larmurier, I.; Beaugerier, L.; Cosnes, J.; Corthier, G.; Marteau, P.; Dore, J. Low counts of Faecalibacterium prausnitzii in colitis microbiota. Inflamm. Bowel Dis. 2009, 15, 1183-1190. 
40. Png, C.W.; Linden, S.K.; Gilshenan, K.S.; Zoetendal, E.G.; McSweeney, C.S.; Sly, L.I.; McGuckin, M.A.; Florin, T.H. Mucolytic bacteria with increased prevalence in IBD mucosa augment in vitro utilization of mucin by other bacteria. Am. J. Gastroenterol. 2010, 105, 2420-2428.

41. Willing, B.P.; Dicksved, J.; Halfvarson, J.; Andersson, A.F.; Lucio, M.; Zheng, Z.; Jarnerot, G.; Tysk, C.; Jansson, J.K.; Engstrand, L. A pyrosequencing study in twins shows that gastrointestinal microbial profiles vary with inflammatory bowel disease phenotypes. Gastroenterology 2010, 139, 1844-1854.

42. Joossens, M.; Huys, G.; Cnockaert, M.; De Preter, V.; Verbeke, K.; Rutgeerts, P.; Vandamme, P.; Vermeire, S. Dysbiosis of the fecal microbiota in patients with Crohn's disease and their unaffected relatives. Gut 2011, 60, 631-637.

43. Erickson, A.R.; Cantarel, B.L.; Lamendella, R.; Darzi, Y.; Mongodin, E.F.; Pan, C.; Shah, M.; Halfvarson, J.; Tysk, C.; Henrissat, B.; et al. Integrated metagenomics/metaproteomics reveals human host-microbiota signatures of Crohn's disease. PLoS One 2012, 7, e49138.

44. Rajilic-Stojanovic, M.; Shanahan, F.; Guarner, F.; De Vos, V.M. Phylogenetic analysis of dysbiosis in ulcerative colitis during remission. Inflamm. Bowel Dis. 2013, 19, 481-488.

45. Varela, E.; Manichanh, C.; Gallart, M.; Torrejon, A.; Borruel, N.; Casellas, F.; Antolin, M. Colonisation by Faecalibacterium prausnitzii and maintenance of clinical remission in patients with ulcerative colitis. Aliment. Pharmacol. Ther. 2013, 38, 151-161.

46. Bucker, R.; Schulz, E.; Gunzel, D.; Bojarski, C.; Lee, I.F.; John, L.J.; Wiegand, S.; JanBen, T.; Wieler, L.H.; Dobrindt, U.; et al. $\alpha$-hemolysin of Escherichia coli in IBD: A potentiator of inflammatory activity of the colon. Gut 2014, doi:10.1136/gutjnl-2013-306099.

47. Nguyen, H.T.; Dalmasso, G.; Muller, S.; Carriere, J.; Seibold, F.; Darfeuille-Michaud, A. Crohn's disease-associated adherent invasive Escherichia coli modulate levels of microRNAs in intestinal epithelial cells to reduce autophagy. Gastroenterology 2014, 146, 508-519.

48. Kagnoff, M.F.; Eckmann, L. Epithelial cells as sensors for microbial infection. J. Clin. Invest. 1997, 100, 6-10.

49. Kim, M.; Ashida, H.; Ogawa, M.; Yoshikawa, Y.; Mimuro, H.; Sasakawa, C. Bacterial interactions with the host epithelium. Cell Host Microbe. 2010, 8, 20-35.

50. Autschbach, F.; Eisold, S.; Hinz, U.; Zinser, S.; Linnebacher, M. High prevalence of Mycobacterium avium subspecies paratuberculosis IS900 DNA in gut tissues from individuals with Crohn's disease. Gut 2005, 54, 944-949.

51. Peyrin-Biroulet, L.; Neut, C.; Colombel, J.F. Antimycobacterial therapy in Crohn's disease: Game over? Gastroenterology 2007, 132, 2594-2598.

52. Vanderploeg, R.; Panaccione, R.; Ghosh, S.; Rioux, K. Influences of Intestinal Bacteria in Human Inflammatory Bowel Disease. Infect. Dis. Clin. N. Am. 2010, 24, 977-993.

53. Kirkwood, C.D.; Wagner, J.; Boniface, K.; Vaughan, J.; Michalski, W.P.; Catto-Smith, A.G.; Cameron, D.J.; Bishop, R.F. Mycobacterium avium supspecies paratuberculosis in children with early-onset Crohn's disease. Inflamm. Bowel. Dis. 2009, 15, 1643-1655.

54. Jostins, L.; Ripke, S.; Weersma, R.K.; Duerr, R.H.; McGovern, D.P.; Hui, K.Y.; Lee, J.C.; Schumm, L.P.; Sharma, Y.; Anderson, C.A.; et al. Host-microbe interactions have shaped the genetic architecture of inflammatory bowel disease. Nature 2013, 491, 119-124. 
55. Selby, W.; Pavli, P.; Crotty, B.; Florin, T.; Radford-Smith, G.; Gibson, P.; Mitchell, B.; Connell, W.; Read, R.; Merret, M.; et al. Two-year combination antibiotic therapy with clarithromycin, rifabutin, and clofazimine for Crohn's disease. Gastroenterology 2007, 132, 2313-2319.

56. Chamberlain, W. Importance of the Australian Crohn's Disease Antibiotic Study. Gastroenterology 2007, 133, 1744-1745.

57. Khosravi, A.; Mazmanian, S.K. Disruption of the gut microbiome as a risk factor for microbial infections. Curr. Opin. Microbiol. 2013, 16, 221-227.

58. Reid, G.; Howard, J.; Gan, B.S. Can bacterial interference prevent infection? Trends. Microbiol. 2001, 9, 424-428.

59. Tazoe, H.; Otomo, Y.; Kaji, I.; Tanaka, R.; Karaki, S.I.; Kuwahara, A. Roles of short-chain fatty acids receptors, GPR41 and GPR43 on colonic functions. J. Physiol. Pharmacol. 2008, 59, 251-262.

60. Vinolo, M.; Rodrigues, H.G.; Nachbar, R.T.; Curi, R. Regulation of Inflammation by Short Chain Fatty Acids. Nutrients 2011, 3, 858-876.

61. Roth, J.; Szule, A.L.; Danoff, A. Energy, evolution, and human diseases: An overview. Am. J. Clin. Nutr. 2011, 93, 75-83.

62. Cani, P.D. Gut microbiota and obesity: Lessons from the microbiome. Brief. Funct. Genomics 2013, 12, 381-387.

63. Ley, R.E.; Backhed, F.; Turnbaugh, P.; Lozupone, C.A.; Knight, R.D.; Gordon, J.I. Obesity alters gut microbial ecology. Proc. Natl. Acad. Sci. USA 2005, 102, 11070-11075.

64. Tumbaugh, P.J.; Ridaura, V.K.; Faith, J.J.; Rey, F.E.; Knight, R.; Gordon, J.I. The effect of diet on the human gut microbiome: A metagenomic analysis in humanized gnotobiotic mice. Sci. Transl. Med. 2009, 1, 6ra14.

65. Gauffin, C.P.; Santacruz, A.; Moya, A.; Sanz, Y. Bacterioides uniformis CECT 7771 ameliorates metabolic and immunological dysfunction in mice with high-fat-diet incuced obesity. PLoS One 2012, 7, e41079.

66. Geurts, L.; Lazarevic, V.; Derrien, M.; Everard, A.; Van Roye, M.; Knauf, C.; Valet, P.; Girard, M.; Muccioli, G.G.; Francois, P. Altered gut microbiota and endocannadbinoid system tone in obese and diabetic leptin-resistant mice: Impact on apelin regulation in adipose tissue. Front. Microbiol. 2011, 2, 149.

67. Tumbaugh, P.J.; Ley, R.E.; Mahowald, M.A.; Magrini, V.; Mardis, E.R.; Gordon, J.I. An obesity-associated gut microbiome with increased capacity for energy harvest. Nature 2006, 444, $1027-1031$.

68. Moran, G.W.; Dubeau, M.F.; Kaplan, G.G.; Panaccione, R.; Ghosh, S. The increasing weight of Crohn's disease subjects in clinical trials: A hypothesis-generating time-trend analysis. Inflamm. Bowel Dis. 2013, 19, 2949-2956.

69. Yatsunenko, T.; Rey, F.E.; Manary, M.J.; Trehan, I.; Dominguez-Bello, M.G.; Contreras, M.; Magris, M.; Hidalgo, G.; Baldassano, R.N.; Anokhin, A.P. Human gut microbiome viewed across age and geography. Nature 2012, 486, 222-227.

70. Muegge, B.D.; Kuczynaki, J.; Knights, D.; Clemente, J.C.; Gonzalez, A.; Fontana, L.; Henrissat, B.; Knight, R.; Gordon, J.I. Diet drives convergence in gut microbiome functions across mammalian phylogeny and within humans. Science 2011, 332, 970-974. 
71. Human Microbiome Project Consortium. Nature, Structure, Function and Diversity of the Healthy Human Microbiome. Nature 2012, 486, 207-214.

72. Morgan, X.C.; Tickle, T.L.; Sokol, H.; Gevers, D.; Devaney, K.L.; Ward, D.V.; Reyes, J.A.; Shah, S.A.; LeLeiko, N.; Snapper, S.B.; et al. Dysfunction of the intestinal microbiome in inflammatory bowel disease and treatment. Genome. Biol. 2012, 13, R79.

73. Rowan, F.; Docherty, N.G.; Murphy, M.; Murphy, B.; Calvin, C.J.; O’Connell, P.R. Desulfovibrio bacterial species are increased in ulcerative colitis. Dis. Colon Rectum 2010, 53, $1530-1536$.

74. Cosnes, J.; Carbonnel, F.; Beaugerie, L.; Le Quintrec, Y.; Gendre, J.P. Effects of cigarette smoking on the long-term course of Crohn's disease. Gastroenterology 1996, 110, 424-431.

75. Mahid, S.S.; Minor, K.S.; Soto, R.E.; Hornung, C.A.; Galandiuk, S. Smoking and inflammatory bowel disease: A meta-analysis. Mayo. Clin. Proc. 2006, 81, 1462-1471.

76. Biedermann, L.; Zeitz, J.; Mwinyi, J.; Sutter-Minder, E.; Rehman, A.; Ott, S.J.; Steurer-Stey, C.; Frei, A.; Frei, P.; Scharl, M.; et al. Smoking Cessation Induces Profound Changes in the Composition of the Intestinal Microbiota in Humans. PLoS One 2013, 8, 1-8.

77. Ley, R.E.; Tumbaugh, P.J.; Klein, S.; Gordon, J.I. Microbial Ecology: Human gut microbes associated with obesity. Nature 2006, 444, 1022-1023.

78. Butaye, P.; Devriese, L.A.; Haesebrouck, F. Antimicrobial growth promoters used in animal feed: effects of less well known antibiotics on gram-positive bacteria. Clin. Microbiol. Rev. 2003, $16,175-188$.

79. Jukes, T.H. Antibiotics in animal feeds and animal production. Bioscience 1972, 22, 526-534.

80. Cho, I.; Yamanishi, S.; Cox, L.; Methe, B.A.; Zavadi, J.; Li, K.; Gao, Z.; Mahana, D.; Raju, K.; Teitler, I.; et al. Antibiotics in early life alter the murine colonic microbiome and adiposity. Nature 2012, 488, 621-626.

81. Cho, I.; Blaser, M.J. The human microbiome: At the interface of health and disease. Nat. Rev. Genet. 2012, 13, 260-270.

82. Ursing, B.; Alm, T.; Barany, F.; Bergelin, I.; Ganrot-Norlin, K.; Hoevels, J.; Huitfeld, B.; Jarnerot, G.; Krause, U.; Krook, A.; et al. A comparative study of metronidazole and sulfasalazine for active Crohn's disease: The cooperative Crohn's disease study in Sweden. Gastroenterology 1982, 83, 550-562.

83. Sutherland, L.; Singleton, J.; Sessions, J.; Hanauer, S.; Krawitt, E.; Rankin, G.; Summers, R.; Mekhjian, H.; Greenberger, N.; Kelly, M. Double blind, placebo controlled trial of metronidazole in Crohn's disease. Gut 1991, 32, 1071-1075.

84. Prantera, C.; Lochs, H.; Grimaldi, M.; Danese, S.; Scribano, M.L.; Gionchetti, P. Rifaximin-extended intestinal release induces remission in patients with moderatively active Crohn's disease. Gastroenterology 2012, 142, 473-481.

85. Khan, K.J.; Ullman, T.A.; Ford, A.C.; Abreu, M.T.; Abadir, A.; Marshall, J.K.; Talley, N.J.; Moayyedi, P. Antibiotic therapy in inflammatory bowel disease: A systematic review and meta-analysis. Am. J. Gastroenterol. 2011, 106, 661-673.

86. Wang, S.L.; Wang, Z.R.; Yang, C.Q. Meta-analysis of broad-spectrum antibiotic therapy in patients with active inflammatory bowel disease. Exp. Ther. Med. 2012, 4, 1051-1056. 
87. Gilliland, S.E.; Morelli, L.; Gregor, R. Health and nutritional properties of probiotics in food including powder milk with live lactic acid bacteria. Avaiable online: www.who.int/foodsafety/ publications/fs_management/en/probiotics.pdf?ua=1 (accessed on 23 March 2014).

88. Schultz, M.; Veltkamp, C.; Dieleman, L.A.; Wetonia, B.G.; Wyrick, P.B.; Tonkonogy, S.L.; Sartor, R.B. Lactobacillus plantarum $299 \mathrm{~V}$ in the treatment and prevention of spontaneous colitis in interleukin-10-deficient mice. Inflamm. Bowel Dis. 2002, 8, 71-80.

89. Madsen, K.L.; Doyle, J.S.; Jewell, L.D.; Tavernini, M.M.; Fedorak, R.N. Lactobacillus species prevents colitis in interleukin 10 gene-deficient mice. Gastroenterology 1999, 116, 1107-1114.

90. O’Mahony, L.; Feeney, M.; O’Halloran, S.; Murphy, L.; Kiely, B.; Fitzgibbon, J.; Lee, G.; O’Sullivan, G.; Shanahan, F.; Collins, J.K. Probiotic impact on microbial flora, inflammation and tumour development in IL-10 knockout mice. Aliment. Pharmacol. Ther. 2001, 15, 1219-1225.

91. Jonkers, D.; Stockbrugger, R. Probiotics and inflammatory bowel disease. J. Roy. Soc. Med. 2003, 96, 167-171.

92. Guarner, F. Prebiotics in inflammatory bowel diseases. Br. J. Nutr. 2007, 98, S85-S90.

93. Guy, P.R. Coprophagy in the African elephant (Loxadonta africana Blumenbach). Afr. J. Ecol. 1977, 15, 174.

94. Payne, C.L.R.; Webster, T.H.; Hunt, K.D. Coprophagy by the semi-habituated chimpanzees of Semliki, Uganda. Pan Afr. News 2008, 15, 29-32.

95. Petrof, E.O.; Khoruts, A. From Stool Transplants to Next-generation Microbiota Therapeutics. Gastroenterology 2014, 146, 1573-1582.

96. Zhang, F.; Luo, W.; Shi, Y.; Fan, Z.; Ji, G. Should we standardize the 1700-year-old fecal microbiota transplantation? Am. J. Gastroenterol. 2012, 107, 1755.

97. Kassam, Z.; Lee, C.H.; Yuan, Y.; Hunt, R.H. Fecal microbiota transplantation for Clostridium difficile infection: Systematic review and meta-analysis. Am. J. Gastroenterol. 2013, 108, 500-508.

98. Tosh, P.K.; McDonald, L.C. Infection control in the multidrug-resistant era: Tending the human microbiome. Clin. Infect. Dis. 2012, 54, 707-713.

99. Petrof, E.O.; Claud, E.C.; Gloor, G.B.; Allen-Vercoe, E. Microbial ecosystems therapeutics: A new paradigm in medicine? Benef. Microbes 2013, 4, 53-65.

100. Bennet, J.D.; Brinkman, M. Treatment of ulcerative colitis by implantation of normal colonic flora. Lancet 1989, 1, 164.

101. Borody, T.J.; Warren, E.F.; Leis, S.; Surace, R.; Ashman, O. Treatment of ulcerative colitis using fecal bacteriotherapy. J. Clin. Gastroenterol. 2003, 37, 42-47.

102. Kump, P.K.; Grochenig, H.; Lackner, S.; Trajanoski, S.; Reicht, G.; Hoffman, M.; Deutschmann, A.; Wenzl, H.H.; Petritsch, W.; Krejs, G.J.; et al. Alteration of intestinal dysbiosis by fecal microbiota transplantation does not induce remission in patients with chronic active ulcerative colitis. Inflamm. Bowel Dis. 2013, 19, 2155-2165.

103. Jacobasch, G.; Schmiedl, D.; Kruschewski, M.; Schmehl, K. Dietary resistant starch and chronic inflammatory bowel diseases. Int. J. Colorectal Dis. 1999, 14, 201-211.

104. Rodriguez-Cabezas, M.E.; Galvez, J.; Lorente, M.D.; Concha, A.; Camuesco, D.; Azzouz, S.; Osuna, A.; Redondo, L.; Zarzuelo, A. Dietary fiber down-regulates colonic tumor necrosis factor alpha and nitric oxide production in trinitrobenzenesulfonic acid-incuded colitic rats. J. Nutr. 2002, 132, 3263-3271. 
105. Vieira, E.L.M.; Leonel, A.J.; Sad, A.P.; Beltrao, N.R.M.; Costa, T.F.; Ferreira, T.M.R.; Gomes-Santos, A.C.; Faria, A.M.C.; Peluzio, M.C.G.; Cara, D.C.; et al. Oral administration of sodium butyrate attentuates inflammation and mucosal lesion in experimental acute ulcerative colitis. J. Nutr. Biochem. 2011, 23, 430-436.

106. Antonopoulos, D.A.; Huse, S.M.; Morrison, H.G.; Schmidt, T.M.; Sogin, M.L.; Young, V.B. Reproducible community dynamics of the gastrointestinal microbiota following antibiotic perturbation. Infect. Immun. 2009, 77, 2367-2375.

107. Dethlefsen, L.; Relman, D.A. Incomplete recovery and individualized responses of the human distal gut microbiota to repeated antibiotic perturbation. Proc. Natl. Acad. Sci. USA 2011, 108, $4554-4561$.

108. Pitout, J.D. IPSAT P1A, a class A beta-lactamase therapy for the prevention of penicillin-induced disruption to the intestinal microflora. Curr. Opin. Investig. Drugs 2009, 10, 838-844.

109. Khoder, M.; Tsapis, N.; Domergue-Dupont, V.; Guetin, C.; Fattal, E. Removal of residual colonic ciprofloxacin in the rat by activated charcoal entrapped within zinc-pectinate beads. Eur. J. Pharm. Sci. 2010, 41, 281-288.

110. Ubeda, C.; Taur, Y.; Jenq, R.R.; Equinda, M.J.; Son, T.; Samstein, M.; Viale, A.; Socci, N.D.; Van den Brink, M.R.M.; Kamboj, M. Vancomycin-resistant Enterococcus domination of intestinal microbiota is enabled by antibiotic treatment in mice and precedes bloodstream invasion in humans. J. Clin. Invest. 2010, 120, 4332-4341.

(C) 2014 by the authors; licensee MDPI, Basel, Switzerland. This article is an open access article distributed under the terms and conditions of the Creative Commons Attribution license (http://creativecommons.org/licenses/by/3.0/). 